\title{
Current limitations of murine models in oncology for ascorbate research
}

\section{Elizabeth J. Campbell and Gabi U. Dachs*}

Mackenzie Cancer Research Group, Department of Pathology, University of Otago, Christchurch, New Zealand

Edited by:

Ruggero De Maria, Istituto Superiore

di Sanità, Italy

\section{Reviewed by:}

Alexander Johannes Michels, Oregon

State University, USA

Fiona Harrison, Vanderbilt University

Medical Center, USA

*Correspondence:

Gabi U. Dachs, Mackenzie Cancer

Research Group, Department of

Pathology, University of Otago,

Christchurch, PO Box 8140,

Christchurch 8011, New Zealand

e-mail:gabi.dachs@otago.ac.nz

\begin{abstract}
The role of vitamin $\mathrm{C}$ (ascorbate) in cancer prevention, tumor growth, and treatment is of intense public interest. Clinical trial data have been sparse, contradictory, and highly controversial, and robust pre-clinical data are required for progress. This paper reviews pre-clinical models and their limitations with respect to ascorbate research. Most studies have utilized animals able to synthesize ascorbate and thus are not ideal models of the human condition. More recently, genetically modified mouse models have become available; yet, all studies compared healthy and scorbutic mice. The majority of investigations to date concluded that increased ascorbate led to decreased tumor growth, but data on mechanisms and doses are inconclusive. Clinically relevant animal studies are still required to convince a generally sceptical medical audience of the potential worth of ascorbate as an adjunct to therapy.
\end{abstract}

Keywords: vitamin C, xenograft, gulonolactone oxidase, hypoxia-inducible factor

\section{INTRODUCTION}

Vitamin C (ascorbate) is a small, water soluble molecule derived from glucose. Although most animals synthesize ascorbate in their liver or kidneys, it has become an essential vitamin for human beings due to mutations in the terminal enzyme of its biosynthesis pathway, L-gulonolactone oxidase (Gulo) $(1,2)$. Therefore, human beings, together with other primates, guinea pigs, and some fruit bats, require daily dietary ascorbate to maintain their health and prevent their tissues becoming ascorbate deficient (scorbutic). Although the extreme ascorbate deficiency condition, scurvy, is rare, large proportions of the population are at risk of chronic deficiency (3).

There are a myriad of roles attributed to ascorbate, with some potentially important in cancer risk and progression, but most data are derived from either cell-free or cell culture systems. Ascorbate is a potent antioxidant believed to protect immune cells against intracellular reactive oxygen species formed during the inflammatory response (4). Ascorbate supports both the innate and adaptive immune functions, inhibits excessive activation of the immune system, and maintains natural neutrophil apoptosis, thus preventing tissue damage (5). It supports immune cell activity, especially phagocytosis and T-cell function (4).

Ascorbate is a vital co-factor for a family of enzymes, the nonheme and 2-oxoglutarate-dependent dioxygenases, which control important cellular processes including hormone synthesis, protein structure, epigenetic changes, and response to low oxygen (hypoxia) (6-10). Hypoxia is a characteristic of solid tumors, and the extent of tumor hypoxia has been associated with more aggressive cancers and poor patient outcome (11). Hypoxia-inducible factor 1 (HIF-1) is the master regulator of cellular response to

Abbreviations: HIF-1, hypoxia-inducible factor 1; IP, intraperitoneal; IV, intra venous; $\mathrm{PO}$, per os (by mouth); SC, subcutaneous. hypoxia, and HIF-1 levels and activity are under control of hydroxylase enzymes that require ascorbate as a co-factor (9). Ascorbate is essential for the development and maintenance of connective tissues and wound healing, via the synthesis of collagen. Collagen fibers form part of the extracellular matrix, a vital component of solid tumors. In cell culture studies, collagen increased directional migration of tumor cells, and introduction of ascorbate into the media reduced this metastatic phenotype (12).

The functional role of ascorbate in cancer biology is complex and remains unclear. Therefore, relevant animal models are crucial for investigating its role during tumor growth and cancer therapy. In contrast to cell culture systems, these in vivo models provide a complex microenvironment, which contains the appropriate physiological, immunological, and biomechanical components to model heterogeneous tumor growth. This review will give an overview of published data in animal models where the effect of ascorbate on cancer was investigated. We have divided animal models into two broad categories: ascorbate-synthesizing or ascorbate-dependent models.

\section{ASCORBATE-SYNTHESIZING ANIMALS}

Virtually all laboratory animals, including inbred wild type mice and immune-deficient murine models, can synthesize their own ascorbate.

\section{WILD TYPE MICE WITH MURINE TUMORS}

Inbred wild type mice (e.g., C57BL/6, BALB/c, and C3H) have been used for $>50$ years to investigate tumor growth and treatment response. These mice have a fully competent immune response, which allows the study of the role of the immune system during therapy, but require mouse-strain specific murine tumor models (syngeneic tumors). A pharmacokinetic study in C57BL/6 mice following either IV or IP injection $(1 \mathrm{~g} / \mathrm{kg})$ of ascorbate showed that plasma ascorbate can reach millimolar levels (13). 
Although IV administration resulted in an immediate increase in plasma concentrations $(>20 \mathrm{mM}), 1 \mathrm{~h}$ after administration there was little difference between IV and IP plasma ascorbate levels $(\sim 6 \mathrm{mM})$. Using BALB/c mice, Yeom et al. (14) showed that high-dose ascorbate injections $(30 \mathrm{mg} /$ mouse $\sim 1 \mathrm{~g} / \mathrm{kg}$ ) inhibited sarcoma 180 tumor growth, and, dependent on time of administration, could play a preventative or therapeutic role through reduction of angiogenesis (14). Similarly, continuous high-dose IP injections $(4 \mathrm{~g} / \mathrm{kg}$ ) produced a reduction in hormone-refractory prostate tumor volume and a decrease in metastatic lesions of over $50 \%$ (15). Furthermore, tumor growth of Lewis lung carcinomas and metastatic spread were reduced using a combination of IP vitamin $\mathrm{C}$ and vitamin $\mathrm{K}$ (16).

The maximum plasma levels achieved following injection with high-dose ascorbate in patients are about 100-fold higher than those achievable via dietary intake (17). Similarly, oral dosing in mice $(6 \mathrm{~g} / \mathrm{L})$ did not reach pharmacological plasma levels (13). Combined treatment of ascorbate with vitamin $\mathrm{K}$ at dietary levels increased murine lifespan by $45 \%$ (18) and reduced metastasis in a liver cancer model (19). However, as ascorbate was not tested separately, its contribution is unclear.

From these reports, there appears to be an anti-tumor effect at high-dose ascorbate in wild type mice bearing syngeneic tumors.

\section{IMMUNE-COMPROMISED MICE WITH HUMAN TUMOR XENOGRAFTS}

The nude $(\mathrm{Nu} / \mathrm{Nu})$ mouse $(20,21)$ has been used in oncology for decades to characterize the growth, spread, and drug responses of human tumors (xenografts). This mouse strain has a mutation on chromosome 11 (Foxn1nu-), resulting in an absent thymus and greatly reduced number of T-cells, yet is able to mount a limited immune response (22-24). Human pancreatic tumor xenografts in nude mice treated with pharmacological levels of ascorbate ( $4 \mathrm{~g} / \mathrm{kg}$ daily) were significantly smaller than untreated controls (7) and, using the same dosage, tumor volume of human ovarian, pancreatic, and glioblastoma models was significantly reduced $(>40 \%)(25,26)$. Similarly, daily IP injections of lower doses of ascorbate $(0.15 \mathrm{~g} / \mathrm{kg})$ were associated with a reduction in tumor growth of human colorectal cancer xenografts (WiDr) (27), although this study was limited by small numbers per treatment group $(n=5)$. Human erythromyeloid leukemia tumors (K562), grown in nude mice, showed a $60 \%$ reduction in size compared to controls 4 weeks after a single IP injection of a combination of ascorbate/menadione ( $1 \mathrm{~g} / \mathrm{kg}$ and $10 \mathrm{mg} / \mathrm{kg}$, respectively) (28).

Severe combined immune deficiency (SCID) mice carry a mutation on chromosome 16 (DNA repair enzyme Prkdc ${ }^{-}$) and have lost the ability to produce B- and T-cells. However, these mice still contain low number of leukocytes and produce normal numbers of natural killer cells (29). Importantly, this mouse strain is unable to fight infections or reject tumors, and is, therefore, used widely in drug development studies using human tumor xenografts. When SCID mice were supplemented with ascorbate $(5 \mathrm{~g} / \mathrm{L})$ in their drinking water, growth of human lymphoma xenografts was reduced, and this was attributed to an associated reduction in the transcription factor HIF-1 (30). In contrast, a study using prostate xenografts grown in SCID mice showed that PO $(40 \mathrm{mg} / \mathrm{kg}$ or $500 \mathrm{mg} / \mathrm{kg})$ administration of ascorbate was not sufficient to reduce tumor growth (31). Pharmacokinetic analysis conducted in this study indicated that plasma levels were elevated and maintained for at least $6 \mathrm{~h}(31)$, which is different to previous reports (13).

In summary, data from immune-compromised mice indicate an anti-tumor effect with high-dose ascorbate, dependent on dose and route of administration (Table $\mathbf{1}$ ).

\section{CARCINOGEN-INDUCED TUMORS IN ASCORBATE-SYNTHESIZING ANIMALS}

The potential role of ascorbate in the prevention of carcinogenesis has been investigated for many years, and recent studies are summarized here. The effect of dietary ascorbate on oestrogen-induced breast carcinogenesis was investigated in August Copenhagen Irish (ACI) rats (35). Ascorbate attenuated oestrogen-induced alterations in oxidative stress markers and enzyme activity, and reduced incidence of neoplastic lesions. In contrast, in some strains of rats, ascorbate increased carcinogen-induced bladder carcinoma $(\mathrm{N}$ butyl- $N$-(4-hydroxybutyl)-nitrosamine), but in others it made no difference $(36,37)$. Similarly, in SKH-1 hairless mice exposed to genotoxic UV light, dietary ascorbate increased pre-cancerous and malignant skin lesions (38). The impact of ascorbate on carcinogenesis, therefore, remains unresolved.

In summary, few studies measured plasma levels and none measured tumor ascorbate levels, which is a vital starting point for mechanistic studies. Studies were difficult to compare, due to different doses and administration routes of ascorbate (Table 1). Most studies investigated high-dose ascorbate, and no clear molecular mechanisms were reported.

\section{ASCORBATE-DEPENDENT ANIMALS}

A number of early studies investigated ascorbate levels and tumor progression in the naturally deficient rodent, the guinea pig (3941). In guinea pigs, ascorbate was reportedly preferentially taken up in tumor tissue (Dael and Biltris sarcoma) following IV injection of $50 \mathrm{mg}$ ascorbate (42). Intermittent scurvy increased the frequency of carcinogen-induced tumors compared to healthy guinea pigs (43). In contrast, another study showed that increased ascorbate supplementation was associated with more rapidly growing tumors (41). In this study, guinea pigs, maintained on a scorbutic diet $(0.3 \mathrm{mg} / \mathrm{kg} /$ day $)$, showed increased tumor regression compared to animals maintained on higher doses $(10 \mathrm{mg} / \mathrm{kg} /$ day or $1 \mathrm{~g} / \mathrm{kg}$ /day), suggesting that tumors required ascorbate for growth. More recently, injection of ascorbate $(500 \mathrm{mg} / \mathrm{kg} / \mathrm{day} \mathrm{SC}$ ) or oral supplementation were shown to inhibited tumor growth in guinea pigs (44). Tumor growth was inversely correlated with tumor ascorbate levels, and when tumor ascorbate exceeded $1 \mathrm{mM}$, tumor growth was inhibited in $>50 \%$ of animals. Thus, conflicts in the guinea pig data remain unresolved.

Improvements in genetic modifications have led to the production of a range of specific mouse models to study the role of ascorbate (Table 2). These genetically modified models contain deficiencies in ascorbate transporters and deficiencies in key points of the biosynthetic pathway.

\section{MICE DEFICIENT IN GULONOLACTONE OXIDASE}

$\mathrm{Gulo}^{-1-}$ mice are genetically modified C57BL/6 mice, which contain deletions in exons 3 and 4 of L-gulonolactone oxidase, rendering the enzyme inactive, and resulting in animals that require 


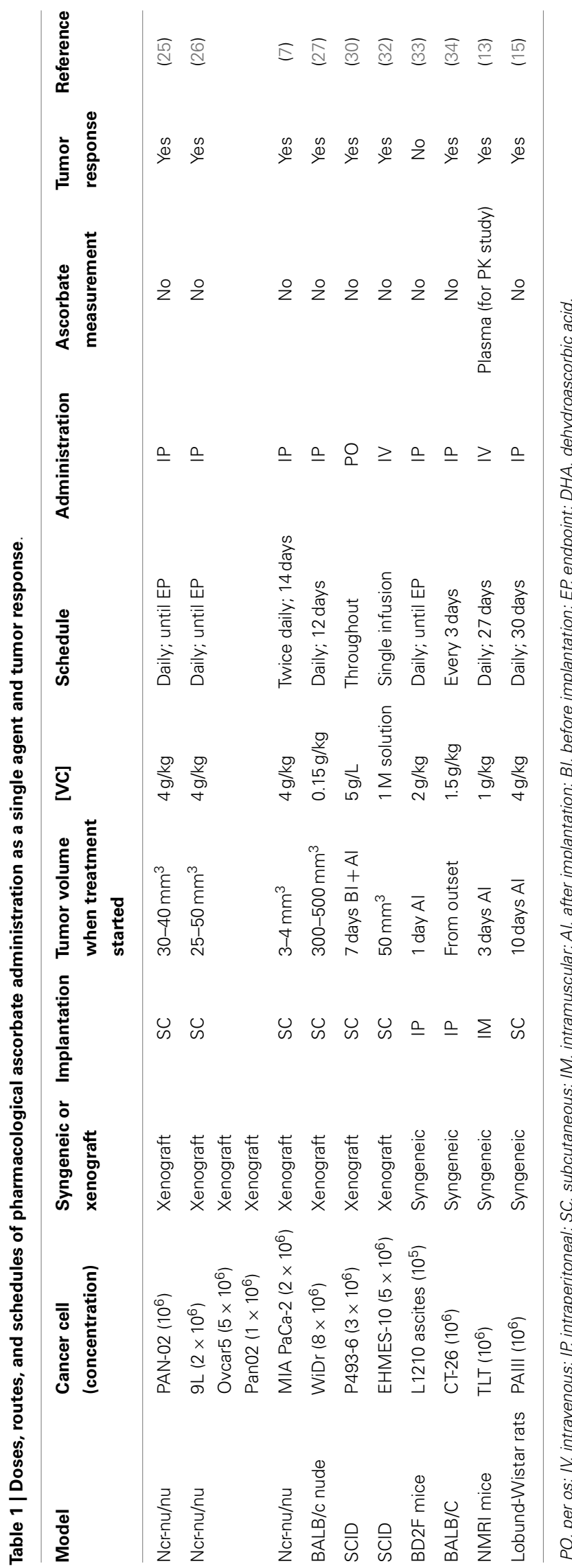

daily ascorbate supplementation, similar to human beings (45). As these animals have fully functional immune systems, they grow only syngeneic murine tumors.

Supplemented $\mathrm{Gulo}^{-/}$mice (500 ppm L-ascorbyl-2polyphosphate with $150 \mathrm{mg} / \mathrm{L}$ ascorbate in drinking water) implanted with either $4 \mathrm{TI}$ breast tumors or B16F0 melanoma cells, showed reduced tumor growth and metastases compared with unsupplemented mice (50). Un-supplemented mice had ascorbate completely withdrawn for 4 weeks prior to tumor implantation, which has previously been shown to result in undetectable levels of ascorbate in plasma and most tissues, a significant reduction in mouse weight, and classical symptoms of scurvy and severe ill health (51). Using an ovarian tumor model, Kim et al. (52) showed that supplementation with oral ascorbate $(1 \mathrm{~g} / \mathrm{L})$ reduced tumor growth and prolonged the onset of disease progression in tumor bearing $\mathrm{Gulo}^{-/-}$mice, again in comparison to un-supplemented mice (52). Conflicting data were reported by Telang et al. (53), who showed that ascorbate depletion resulted in restricted tumor growth of Lewis lung carcinoma via restriction of angiogenesis, suggesting that a reduction of ascorbate may be a therapeutic approach (53).

Ascorbate uptake has been investigated in $\mathrm{Gulo}^{-/-}$mice $(54,55)$. Depletion of ascorbate led to enhanced expression of the SVCT transporters in the liver, small intestine, and cerebellum, with an associated increase in ascorbate uptake in isolated hepatocytes from $\mathrm{Gulo}^{-/-}$mice compared with wild type mice $(54,55)$.

"Spontaneous fracture" or " $S f x$ " mice are an inbred strain in a $\mathrm{BALB} / \mathrm{c}$ genomic background. These mice were first described to contain an autosomaly recessive mutation, in which litter mates were phenotypically identical until $\sim 6$ weeks old when body mass, bone, and metabolic function decreased (47). The $s f x$ gene has since been located to chromosome 14 and it is now known to contain the deletion of all 12 exons in the gene for L-gulonolactone oxidase (46). The Sfx mice require daily supplementation with adequate ascorbate to prevent scurvy, similar to the C57BL/6 $\mathrm{Gulo}^{-/-}$mice. An inverse relationship between the level of ascorbate supplementation and tumor weight of B16F0 tumors was demonstrated in this model (56). In contrast, Parsons et al. (57) found no difference between ascorbate depleted mice and controls in respect to mammary tumor growth (57).

All above studies compared fully supplemented $\mathrm{Gulo}^{-/-}$mice with severely scorbutic animals, which is likely to confound conclusions regarding the impact of ascorbate on cancer.

\section{MICE DEFICIENT IN ASCORBATE TRANSPORTERS}

Ascorbate is transported by two mechanisms, either by direct transport (sodium-dependent vitamin C transporters SVCT1 and 2 ), or by the uptake of dehydroascorbic acid (DHA) via glucose transporters, and subsequent intracellular reduction to ascorbate. SVCT1 is expressed on epithelial tissues such as intestine and kidney, where it contributes to the supply and maintenance of whole-body ascorbate levels, whereas expression of SVCT2 is more widespread, and governs the cellular concentration of ascorbate (58). A recent study in BALB/C mice bearing breast cancer xenografts analyzed the effect in vivo of manipulating tumor SVCT2 levels (59). It demonstrated that an increase of SVCT2 levels was associated with increased tumor growth delay following 
Table 2 | Current ascorbate deficient murine models



GULO, gulonolactone oxidase; KO, knockout; GM, genetically modified; SVCT, sodium-dependant vitamin C transporter.

daily IP ascorbate injections $(1 \mathrm{~g} / \mathrm{kg})$, and a reduction of SVCT2 was associated with a reduction in tumor response (59). These results indicate that intracellular ascorbate concentrations play a major role in tumor response to high-dose vitamin $\mathrm{C}$ treatment.

Although SVCT-knockout mice have been created $(48,49)$, they have not yet been used in cancer research. There is evidence that mice and rats have reduced (SVCT-dependent) ascorbate transport compared to human beings and guinea pigs $(51,60,61)$. This will affect studies on ascorbate transport and metabolism in those animals, but should not impact on research into cancer if plasma and tissue levels are monitored.

\section{MICE DEFICIENT IN ALDEHYDE REDUCTASE AND ALDOSE REDUCTASE}

Recently, the aldehyde reductase (GR) and aldose reductase (AR) double knockout (GRKO/ARKO) mouse has been established on a C57BL/6 background (2). This model silences key enzymes in the ascorbate biosynthetic pathway, leading to a $95 \%$ reduction in liver synthesis of ascorbate. Similar to $\mathrm{Gulo}^{-/-}$mice, these animals will become scorbutic without supplementation. This model has not yet been used in cancer research.

\section{POTENTIAL MECHANISIMS IN CANCER}

There is sparse evidence for the role of ascorbate in the tumor microenvironment, and factors likely to influence tumor response include species, tumor type, size at treatment, whether tumors were grown subcutaneously or orthotopically, ascorbate transporter status, and vascularization, which have all not been rigorously investigated. With the exception of early data in guinea pigs (42), few studies have reported plasma levels and none have investigated tumor ascorbate levels. As tumor ascorbate following intervention in neither human beings nor mice has ever been measured, the optimal dose for maximum tumor concentrations is unknown. A fundamental issue of ascorbate and cancer therapy is the lack of robust data for ascorbate's roles in vivo. Pharmacological versus physiological levels of ascorbate will have significantly different effects.

At pharmacological levels, ascorbate may mediate an antitumor effect via apoptosis $(32,62)$, ATP depletion $(26,63)$, or autophagy (7). High doses of ascorbate are believed to act as prodrug in tissue culture to generate $\mathrm{H}_{2} \mathrm{O}_{2}$ and induce cell kill (64). Chen and colleagues $(26,63)$, have shown that pharmacological levels of ascorbate can induce a pro-oxidant state through $\mathrm{H}_{2} \mathrm{O}_{2}$ production, which may lead to ATP depletion. Du et al. (7) have shown that increased ascorbate concentrations stimulated an apoptotic response and, at pharmacological levels of ascorbate, autophagy, consistent with previously published work (65). However, these conclusions were drawn from in vitro studies, and although in vivo work was carried out using the same cell line (MIA Pac-2), the mechanism was inferred and no biomarkers of oxidation were measured.

Pharmacological doses have been used without increased liver toxicity in mice $(14,26)$, and these doses have been shown to potentiate the cytotoxtic effect of some chemotherapeutic drugs in mice $(28,66,67)$, whilst offering cardioprotection from the cytotoxic side effects (68-70). One notable exception was reported by Heaney et al. (71), who demonstrated a reduction in efficacy of a range of chemotherapeutic agents when given in combination with DHA (71). DHA, the oxidized form of ascorbate, circulates at low levels in vivo of about $2-10 \mu \mathrm{M}$ compared with $50-70 \mu \mathrm{M}$ of ascorbate, and is thus unlikely to play a major role (72).

At physiological levels, the role of ascorbate in the control of HIF-1 is the most investigated and plausible pathway to date. In vitro cell culture and enzyme studies have provided robust mechanistic data of the role of ascorbate as co-factor for the oxygen-sensing HIF hydroxylases $(5,73-75)$, although this has been refuted (76). In all other studies, increasing ascorbate levels were associated with reduced HIF-1 levels in vitro (10) and in vivo (30). In addition, levels of two targets of HIF-1, the metalloenzymes MMP-2 and 9, were significantly reduced in the presence of increased ascorbate (16).

However, all current in vivo data are based either on highdose treatment in ascorbate-synthesizing mice $(25,26,30)$ or dietary interventions in ascorbate-dependent animals, but comparing healthy and scorbutic mice $(50,53)$, and may, therefore, not be relevant for human beings. As tumor levels have not systematically been measured following high-dose ascorbate treatment in these mouse studies, it is unclear whether pharmacological, toxic levels were achieved, thus accounting for an anti-tumor effect via the proposed production of $\mathrm{H}_{2} \mathrm{O}_{2}$. Or, alternatively, whether these high doses were required to overcome the poor vascularization characteristic of solid tumors, thus achieving physiological concentrations and regulating factors such as HIF-1 via ascorbate's co-factor role. Levels and function of ascorbate transporters, SVCT1 and SVCT2, in tumor tissue have only recently started to be investigated (59), and differences between species will affect tissue 
levels (61). The other potential roles of ascorbate during cancer growth, such as epigenetic changes and immune function, have also not been investigated.

\section{CONCLUSION}

Ascorbate could be an inexpensive addition to standard cancer treatment if proven effective. Current animal models have provided evidence of, and some mechanistic insight into, the anti-tumor effects of ascorbate. However, the limited use of suitable ascorbate dependent, yet non-scorbutic, models has limited the strength of the evidence. In addition to using ascorbatesynthesizing animals, many studies are weakened by using a wide range of doses and administration routes that are inconsistent among studies, and seldom measure circulating or tissue ascorbate levels. The role of species-specific gene regulation of ascorbate synthesis and transport may further complicate translation from animals into patients. Hence, carefully conducted, clinically relevant, pre-clinical studies are still required to convince a generally sceptical medical audience of the potential worth of ascorbate as an adjunct to therapy.

\section{REFERENCES}

1. Linster CL, Van Schaftingen E. Vitamin C: biosynthesis, recycling and degradation in mammals. FEBS J (2007) 274(1):1-22. doi:10.1111/j.1742-4658.2006. 05607.x

2. Gabbay KH, Bohren KM, Morello R, Bertin T, Liu J, Vogel P. Ascorbate synthesis pathway: dual role of ascorbate in bone homeostasis. J Biol Chem (2010) 285(25):19510-20. doi:10.1074/jbc.M110.110247

3. Ben-Zvi GT, Tidman MJ. Be vigilant for scurvy in high-risk groups. Practitioner (2012) 256(1755):23-5.

4. Ströhle A, Wolters M, Hahn A. Micronutrients at the interface between inflammation and infection - ascorbic acid and calciferol: part 1, general overview with a focus on ascorbic acid. Inflamm Allergy Drug Targets (2011) 10(1):54-63. doi:10.2174/187152811794352105

5. Vissers MCM, Gunningham SP, Morrison MJ, Dachs GU, Currie MJ. Modulation of hypoxia-inducible factor- 1 alpha in cultured primary cells by intracellular ascorbate. Free Radic Biol Med (2007) 42(6):765-72. doi:10.1016/j. freeradbiomed.2006.11.023

6. Rebouche CJ. Ascorbic acid and carnitine biosynthesis. Am J Clin Nutr (1991) 54(6):1147S-52S.

7. Du J, Martin SM, Levine M, Wagner BA, Buettner GR, Wang S-H, et al. Mechanisms of ascorbate-induced cytotoxicity in pancreatic cancer. Clin Cancer Res (2010) 16(2):509-20. doi:10.1158/1078-0432.ccr-09-1713

8. Minor EA, Court BL, Young JI, Wang G. Ascorbate induces ten-eleven translocation (Tet) methylcytosine dioxygenase-mediated generation of 5hydroxymethylcytosine. J Biol Chem (2013) 288(19):13669-74. doi:10.1074/jbc. C113.464800

9. Stolze IP, Mole DR, Ratcliffe PJ. Regulation of HIF: prolyl hydroxylases. Novartis Found Symp (2006) 272:15-36. doi:10.1002/9780470035009.ch3

10. Pihlajaniemi T, Myllylä R, Kivirikko KI. Prolyl 4-hydroxylase and its role in collagen synthesis. J Hepatol (1991) 13(Suppl 3):S2-7. doi:10.1016/0168-8278(91) 90002-S

11. Dachs GU, Tozer GM. Hypoxia modulated gene expression: angiogenesis, metastasis and therapeutic exploitation. Eur J Cancer (2000) 36(13):1649-60. doi:10.1016/S0959-8049(00)00159-3

12. Gilkes DM, Bajpai S, Wong CC, Chaturvedi P, Hubbi ME, Wirtz D, et al. Procollagen lysyl hydroxylase 2 is essential for hypoxia-induced breast cancer metastasis. Mol Cancer Res (2013) 11(5):456-66. doi:10.1158/1541-7786.mcr-12-0629

13. Verrax J, Calderon PB. Pharmacologic concentrations of ascorbate are achieved by parenteral administration and exhibit antitumoral effects. Free Radic Biol Med (2009) 47(1):32-40. doi:10.1016/j.freeradbiomed.2009.02.016

14. Yeom C-H, Lee G, Park J-H, Yu J, Park S, Yi S-Y, et al. High dose concentration administration of ascorbic acid inhibits tumor growth in BALB/C mice implanted with sarcoma 180 cancer cells via the restriction of angiogenesis. J Transl Med (2009) 7(1):70. doi:10.1186/1479-5876-7-70
15. Pollard HB, Levine MA, Eidelman O, Pollard M. Pharmacological ascorbic acid suppresses syngeneic tumor growth and metastases in hormone-refractory prostate cancer. In vivo (2010) 24(3):249-55.

16. Chen M-F, Yang C-M, Su C-M, Liao J-W, Hu M-L. Inhibitory effect of vitamin C in combination with vitamin $\mathrm{K} 3$ on tumor growth and metastasis of Lewis lung carcinoma xenografted in C57BL/6 mice. Nutr Cancer (2011) 63(7):1036-43. doi:10.1080/01635581.2011.597537

17. Levine M, Padayatty SJ, Espey MG. Vitamin C: a concentration-function approach yields pharmacology and therapeutic discoveries. Adv Nutr (2011) 2(2):78-88. doi:10.3945/an.110.000109

18. Taper HS, de Gerlache J, Lans M, Roberfroid M. Non-toxic potentiation of cancer chemotherapy by combined $\mathrm{C}$ and $\mathrm{K} 3$ vitamin pre-treatment. Int J Cancer (1987) 40(4):575-9. doi:10.1002/ijc.2910400424

19. Taper HS, Jamison JM, Gilloteaux J, Summers JL, Calderon PB. Inhibition of the development of metastases by dietary vitamin C:K3 combination. Life Sci (2004) 75(8):955-67. doi:10.1016/j.lfs.2004.02.011

20. Pantelouris E. Absence of thymus in a mouse mutant. Nature (1968) 217(5126):370-1. doi:10.1038/217370a0

21. Flanagan S. 'Nude', a new hairless gene with pleiotropic effects in the mouse. Genet Res (1966) 8(3):295-309. doi:10.1017/S0016672300010168

22. Ikehara S, Pahwa RN, Fernandes G, Hansen CT, Good RA. Functional T cells in athymic nude mice. Proc Natl Acad Sci U S A (1984) 81(3):886-8. doi:10.1073/pnas.81.3.886

23. Maleckar JR, Sherman LA. The composition of the T cell receptor repertoire in nude mice. J Immunol (1987) 138(11):3873-6.

24. Takahashi YSA, Sakai T, Endo Y, Osawa N, Shisa H, Honjo T. Mapping of the nu gene using congenic nude strains and in situ hybridization. J Exp Med (1992) 175(3):873-6. doi:10.1084/jem.175.3.873

25. Chen P, Stone J, Sullivan G, Drisko JA, Chen Q. Anti-cancer effect of pharmacologic ascorbate and its interaction with supplementary parenteral glutathione in preclinical cancer models. Free Radic Biol Med (2011) 51(3):681-7. doi:10.1016/j.freeradbiomed.2011.05.031

26. Chen Q, Espey MG, Sun AY, Pooput C, Kirk KL, Krishna MC, et al. Pharmacologic doses of ascorbate act as a prooxidant and decrease growth of aggressive tumor xenografts in mice. Proc Natl Acad Sci U S A (2008) 105(32):11105-9. doi:10.1073/pnas.0804226105

27. Mamede AC, Pires AS, Abrantes AM, Tavares SD, Gonçalves AC, Casalta-Lopes JE, et al. Cytotoxicity of ascorbic acid in a human colorectal adenocarcinoma cell line (WiDr): In vitro and in vivo studies. Nutr Cancer (2012) 64(7):1049-57. doi:10.1080/01635581.2012.713539

28. Verrax J, Stockis J, Tison A, Taper HS, Calderon PB. Oxidative stress by ascorbate/menadione association kills K562 human chronic myelogenous leukaemia cells and inhibits its tumour growth in nude mice. Biochem Pharmacol (2006) 72(6):671-80. doi:10.1016/j.bcp.2006.05.025

29. Bosma MJ, Carroll AM. The SCID mouse mutant: definition, characterization, and potential uses. Annu Rev Immunol (1991) 9(1):323-50. doi:10.1146/ annurev.iy.09.040191.001543

30. Gao P, Zhang H, Dinavahi R, Li F, Xiang Y, Raman V, et al. HIF-dependent antitumorigenic effect of antioxidants in vivo. Cancer Cell (2007) 12(3):230-8. doi:10.1016/j.ccr.2007.08.004

31. Bannerman B, Xu L, Jones M, Tsu C, Yu J, Hales P, et al. Preclinical evaluation of the antitumor activity of bortezomib in combination with vitamin $\mathrm{C}$ or with epigallocatechin gallate, a component of green tea. Cancer Chemother Pharmacol (2011) 68(5):1145-54. doi:10.1007/s00280-011-1591-2

32. Takemura Y, Satoh M, Satoh K, Hamada H, Sekido Y, Kubota S. High dose of ascorbic acid induces cell death in mesothelioma cells. Biochem Biophys Res Commun (2010) 394(2):249-53. doi:10.1016/j.bbrc.2010.02.012

33. Fujita K, Shinpo K, Yamada K, Sato T, Numi H, Shamoto M, et al. Reduction of adriamycin toxicity by ascorbate in mice and Guinea pigs. Cancer Res (1982) 42:309-16.

34. Lee J, Lee G, Park JH, Lee S, Yeom CH, Na B, et al. Proteomic analysis of tumor tissue in CT-26 implanted BALB/C mouse after treatment with ascorbic acid. Cell Mol Biol Lett (2012) 17(1):62-76. doi:10.2478/s11658-011-0035-7

35. Mense SM, Singh B, Remotti F, Liu X, Bhat HK. Vitamin C and $\alpha$-naphthoflavone prevent estrogen-induced mammary tumors and decrease oxidative stress in female ACI rats. Carcinogenesis (2009) 30(7):1202-8. doi:10.1093/carcin/ bgp093

36. Mori S, Kurata Y, Takeuchi Y, Toyama M, Makino S, Fukushima S. Influences of strain and diet on the promoting effects of sodium L-ascorbate in 
two-stage urinary bladder carcinogenesis in rats. Cancer Res (1987) 47(13): 3492-5.

37. Murai T, Mori S, Hosono M, Takashima A, Machino S, Oohara T, et al. Strain differences in sensitivity to the promoting effect of sodium L-ascorbate in a two-stage rat urinary bladder carcinogenesis model. Jpn J Cancer Res (1997) 88(3):245-53. doi:10.1111/j.1349-7006.1997.tb00374.x

38. D’Agostini F, Balansky RM, Camoirano A, De Flora S. Modulation of lightinduced skin tumors by $\mathrm{N}$-acetylcysteine and/or ascorbic acid in hairless mice. Carcinogenesis (2005) 26(3):657-64. doi:10.1093/carcin/bgi008

39. Watson $\mathrm{A}$. The chemical reducing capacity and vitamin $\mathrm{C}$ content of transplantable tumours of the rat and guinea-pig. Br J Exp Pathol (1936) 17(2):124-34.

40. Sure B, Theis RM, Harrelson RT, Farber L. Influence of Walker carcinosarcoma on concentration of ascorbic acid in various endocrines and organs. Am J Cancer (1939) 36(2):252-6. doi:10.1158/ajc.1939.252

41. Migliozzi J. Effect of ascorbic acid on tumour growth. $\mathrm{Br}$ J Cancer (1977) 35(4):448-53. doi:10.1038/bjc.1977.67

42. Boyland E. The selective absorption of ascorbic acid by guinea-pig tumour tissue. Biochem J (1936) 30(7):1221-4.

43. Russell WO, Ortega LR, Wynne ES, Frankel JJ. Studies on methylcholanthrene induction of tumors in scorbutic guinea pigs. Cancer Res (1952) 12(3):216-8.

44. Casciari JJ, Riordan HD, Miranda-Massari JR, Gonzalez MJ. Effects of high dose ascorbate administration on L-10 tumor growth in guinea pigs. P R Health Sci (2005) 24(2):145-50.

45. Maeda N, Hagihara H, Nakata Y, Hiller S, Wilder J, Reddick R. Aortic wall damage in mice unable to synthesize ascorbic acid. Proc Natl Acad Sci U S A (2000) 97(2):841-6. doi:10.1073/pnas.97.2.841

46. Jiao Y, Li X, Beamer W, Yan J, Tong Y, Goldowitz D, et al. A deletion causing spontaneous fracture identified from a candidate region of mouse chromosome 14. Mamm Genome (2005) 16(1):20-31. doi:10.1007/s00335-004-2414-0

47. Beamer WG, Rosen CJ, Bronson RT, Gu W, Donahue LR, Baylink DJ, et al. Spontaneous fracture $(\mathrm{sfx})$ : a mouse genetic model of defective peripubertal bone formation. Bone (2000) 27(5):619-26. doi:10.1016/S8756-3282(00) 00369-0

48. Corpe CP, Tu H, Eck P, Wang J, Faulhaber-Walter R, Schnermann J, et al. Vitamin $\mathrm{C}$ transporter Slc23al links renal reabsorption, vitamin $\mathrm{C}$ tissue accumulation, and perinatal survival in mice. J Clin Invest (2010) 120(4):1069-83. doi:10.1172/jci39191

49. Sotiriou S, Gispert S, Cheng J, Wang Y, Chen A, Hoogstraten-Miller S, et al. Ascorbic-acid transporter Slc23al is essential for vitamin $\mathrm{C}$ transport into the brain and for perinatal survival. Nat Med (2002) 8(5):514-7. doi:10.1038/0502514

50. Cha J, Roomi MW, Ivanov V, Kalinovsky T, Niedzwiecki A, Rath M. Ascorbate supplementation inhibits growth and metastasis of B16FO melanoma and 4T1 breast cancer cells in vitamin C-deficient mice. Int J Oncol (2013) 42(1):55-64. doi:10.3892/ijo.2012.1712

51. Vissers M, Bozonet S, Pearson J, Braithwaite L. Dietary ascorbate intake affects steady state tissue concentrations in vitamin C-deficient mice: tissue deficiency after suboptimal intake and superior bioavailability from a food source (kiwifruit). Am J Clin Nutr (2011) 93(2):292-301. doi:10.3945/ajcn.110.004853

52. Kim J-E, Cho H-S, Yang H-S, Jung D-J, Hong S-W, Hung C-F, et al. Depletion of ascorbic acid impairs NK cell activity against ovarian cancer in a mouse model. Immunobiology (2012) 217(9):873-81. doi:10.1016/j.imbio.2011.12.010

53. Telang S, Clem AL, Eaton JW, Chesney J. Depletion of ascorbic acid restricts angiogenesis and retards tumor growth in a mouse model. Neoplasia (2007) 9(1):47-56. doi:10.1593/neo.06664

54. Meredith ME, Harrison FE, May JM. Differential regulation of the ascorbic acid transporter SVCT2 during development and in response to ascorbic acid depletion. Biochem Biophys Res Commun (2011) 414(4):737-42. doi:10.1016/j.bbrc. 2011.09.146

55. Amano A, Aigaki T, Maruyama N, Ishigami A. Ascorbic acid depletion enhances expression of the sodium-dependent vitamin C transporters, SVCT1 and SVCT2, and uptake of ascorbic acid in livers of SMP30/GNL knockout mice. Arch Biochem Biophys (2010) 496(1):38-44. doi:10.1016/j.abb.2010.01.012

56. Cha J, Roomi MW, Ivanov V, Kalinovsky T, Niedzwiecki A, Rath M. Ascorbate depletion increases growth and metastasis of melanoma cells in vitamin C deficient mice. Exp Oncol (2011) 33(4):226-30.
57. Parsons KK, Maeda N, Yamauchi M, Banes AJ, Koller BH. Ascorbic acidindependent synthesis of collagen in mice. Am J Physiol Endocrinol Metab (2006) 290(6):1131-9. doi:10.1152/ajpendo.00339.2005

58. McCarty MF. Expression and/or activity of the SVCT2 ascorbate transporter may be decreased in many aggressive cancers, suggesting potential utility for sodium bicarbonate and dehydroascorbic acid in cancer therapy. Med Hypotheses (2013) 81(4):664-70. doi:10.1016/j.mehy.2013.07.023

59. Hong SW, Lee SH, Moon JH, Hwang JJ, Kim DE, Ko E, et al. SVCT-2 in breast cancer acts as an indicator for L-ascorbate treatment. Oncogene (2013) 32(12):1508-17. doi:10.1038/onc.2012.176

60. Carr AC, Bozonet SM, Pullar JM, Simcock JW, Vissers MC. Human skeletal muscle ascorbate is highly responsive to changes in vitamin $\mathrm{C}$ intake and plasma concentrations. Am J Clin Nutr (2013) 97(4):800-7. doi:10.3945/ajcn. 112.053207

61. Michels A, Frei B. Myths, artifacts, and fatal flaws: identifying limitations and opportunities in vitamin C research. Nutrients (2013) 5(12):5161-92. doi:10.3390/nu5125161

62. Kang J, Cho D, Kim Y-I, Hahm E, Yang Y, Kim D, et al. L-ascorbic acid (vitamin C) induces the apoptosis of B16 murine melanoma cells via a caspase8-independent pathway. Cancer Immunol Immunother (2003) 52(11):693-8. doi:10.1007/s00262-003-0407-6

63. Chen Q, Espey MG, Sun AY, Lee J-H, Krishna MC, Shacter E, et al. Ascorbate in pharmacologic concentrations selectively generates ascorbate radical and hydrogen peroxide in extracellular fluid in vivo. Proc Natl Acad Sci U S A (2007) 104(21):8749-54. doi:10.1073/pnas.0702854104

64. Du J, Cullen JJ, Buettner GR. Ascorbic acid: chemistry, biology and the treatment of cancer. Biochim Biophys Acta (2012) 1826(2):443-57. doi:10.1016/j. bbcan.2012.06.003

65. Ohtani S, Iwamaru A, Deng W, Ueda K, Wu G, Jayachandran G, et al. Tumor suppressor 101F6 and ascorbate synergistically and selectively inhibit non-small cell lung cancer growth by caspase-independent apoptosis and autophagy. Cancer Res (2007) 67(13):6293-303. doi:10.1158/0008-5472.can-06-3884

66. Ma Y, Chapman J, Levine M, Polireddy K, Drisko J, Chen Q. High-dose parenteral ascorbate enhanced chemosensitivity of ovarian cancer and reduced toxicity of chemotherapy. Sci Transl Med (2014) 6(222):222ra18. doi:10.1126/ scitranslmed.3007154

67. Campbell RA, Sanchez E, Steinberg JA, Baritaki S, Gordon M, Wang C, et al. Antimyeloma effects of arsenic trioxide are enhanced by melphalan, bortezomib and ascorbic acid. Br J Haematol (2007) 138(4):467-78. doi:10.1111/j.13652141.2007.06675.x

68. Park J-H, Davis KR, Lee G, Jung M, Jung Y, Park J, et al. Ascorbic acid alleviates toxicity of paclitaxel without interfering with the anticancer efficacy in mice. Nutr Res (2012) 32(11):873-83. doi:10.1016/j.nutres.2012.09.011

69. Viswanatha Swamy AHM, Wangikar U, Koti B, Thippeswamy AHM, Ronad PM, Manjula D. Cardioprotective effect of ascorbic acid on doxorubicin-induced myocardial toxicity in rats. Indian J Pharmacol (2011) 43(5):507-11. doi:10. 4103/0253-7613.84952

70. Martha KRM, Rosangkima G, Amenla L, Rongpi T, Prasad SB. Cisplatinand dietary ascorbic acid-mediated changes in the mitochondria of Dalton's lymphoma-bearing mice. Fundam Clin Pharmacol (2013) 27(3):329-38. doi:10.1111/j.1472-8206.2011.01019.x

71. Heaney ML, Gardner JR, Karasavvas N, Golde DW, Scheinberg DA, Smith EA, et al. Vitamin $\mathrm{C}$ antagonizes the cytotoxic effects of antineoplastic drugs. Cancer Res (2008) 68(19):8031-8. doi:10.1158/0008-5472.can-08-1490

72. Dhariwal KR, Hartzell WO, Levine M. Ascorbic acid and dehydroascorbic acid measurements in human plasma and serum. Am J Clin Nutr (1991) 54(4):712-6.

73. Knowles HJ, Raval RR, Harris AL, Ratcliffe PJ. Effect of ascorbate on the activity of hypoxia-inducible factor in cancer cells. Cancer Res (2003) 63(8): 1764-8.

74. Kaczmarek M, Timofeeva OA, Karaczyn A, Malyguine A, Kasprzak KS, Salnikow K. The role of ascorbate in the modulation of HIF-1 $\alpha$ protein and HIFdependent transcription by chromium(VI) and nickel(II). Free Radic Biol Med (2007) 42(8):1246-57. doi:10.1016/j.freeradbiomed.2007.01.026

75. Flashman E, Davies SL, Yeoh KK, Schofield CJ. Investigating the dependence of the hypoxia-inducible factor hydroxylases (factor inhibiting HIF and prolyl hydroxylase domain 2) on ascorbate and other reducing agents. Biochem J (2010) 427(1):135-42. doi:10.1042/bj20091609 
76. Nytko KJ, Maeda N, Schläfli P, Spielmann P, Wenger RH, Stiehl DP. Vitamin $\mathrm{C}$ is dispensable for oxygen sensing in vivo. Blood (2011) 117(20):5485-93. doi:10.1182/blood-2010-09-307637

Conflict of Interest Statement: The authors declare that the research was conducted in the absence of any commercial or financial relationships that could be construed as a potential conflict of interest.

Received: 27 June 2014; accepted: 29 September 2014; published online: 14 October 2014.
Citation: Campbell EJ and Dachs GU (2014) Current limitations of murine models in oncology for ascorbate research. Front. Oncol. 4:282. doi: 10.3389/fonc.2014.00282 This article was submitted to Cancer Molecular Targets and Therapeutics, a section of the journal Frontiers in Oncology.

Copyright (C) 2014 Campbell and Dachs. This is an open-access article distributed under the terms of the Creative Commons Attribution License (CC BY). The use, distribution or reproduction in other forums is permitted, provided the original author(s) or licensor are credited and that the original publication in this journal is cited, in accordance with accepted academic practice. No use, distribution or reproduction is permitted which does not comply with these terms. 